\title{
OBITUARY
}

\section{Jonas STEIN Friedenwald}

(1897-1955)

A GREAT tragedy has befallen ophthalmology, a tragedy particularly great for the ophthalmological community of the U.S.A., but equally great for the ophthalmological family of the world. Jonas S. Friedenwald died on November 5, 1955, in hospital at Baltimore, Maryland, after a long illness, at the age of 58.

The name of Friedenwald has long been associated with ophthalmic progress. Harry Friedenwald had created for himself an authoritative position in medical ophthalmology; in 1930 he gave the Doyne Memorial Lecture on Pathological Changes in the Retinal Blood Vessels in Arteriosclerosis and Hypertension. His son, Jonas, attained greater fame in many branches of ophthalmology, excelling both as a clinician and as a pathologist, but much more so in the basic sciences of physiology and biochemistry on which our specialty is founded. In these fields he was unique in the United States and had for many years occupied an unchallenged position in that country as the greatest authority on the scientific aspects of ophthalmology, particularly the mechanism of the formation and the dynamics of the intra-ocular fluid. In his wide scientific interests, his experimental ability, and his mature judgement, he had few equals in any country in the world.

Friedenwald entered Johns Hopkins University, where he took his B.A. degree in 1916, and graduated in medicine in 1920. Thereafter he went to Harvard University where he graduated M.A. in 1922. He returned to Johns Hopkins Hospital, and in 1923 at a surprisingly young age became instructor in ophthalmic pathology in its medical school. When the Wilmer Institute of Ophthalmology was opened in 1926 he was one of the first of its staff. In 1931 he was made Associate Professor of Ophthalmology at Johns Hopkins Medical School where he laboured unceasingly and enthusiastically in both the wards and the laboratories until his death.

During his working life he wrote tirelessly and was the author of more than 140 scientific papers as well as his "Pathology of the Eye". Many honours came his way. In the United States, he won the Research Medal of the American Medical Association (1935), the first Proctor Medal (1949), and the Howe Medal of the American Ophthalmological Society (1951). In 1952 he was presented with the Donders Medal in Holland, and in the coming year he was to have been given the Doyne Medal at the 1956 meeting of the Oxford Ophthalmological Congress.

Although he lived for ophthalmology in its widest aspects, Friedenwald had many other interests. A lover of literature, painting, and music, he was the worthy custodian of the magnificent collection of rare medical books and manuscripts which he inherited from his father. Equally aware of the world of affairs, he took an intense interest in education and all aspects of social progress and in his later years he spent much care in the academic development of Israel.

An able and interesting lecturer, a kindly and shrewd critic in professional meetings, a delightful companion full of enthusiasm for everything that was happening in the world, particularly in the ophthalmological world, a good talker, full of quiet and unassuming humour, Friedenwald was a colleague whom to know well was a joy. His many friends in Great Britain will particularly regret that he will not be with them in Oxford in 1956. Because of his death American ophthalmology-and world ophthalmology-is much the poorer, and many of us have lost one who, while he walked with us, was not only a stimulus but also a friend. 